\title{
Particulate Scale Multiparticle Finite Element Method Modeling on the 2D Compaction and Release of Copper Powder
}

\author{
Liwen Zhou $\left(\mathbb{D}\right.$, Peng Han $\left(\mathbb{D}\right.$, Kun Liu $\left(\mathbb{D}\right.$, Lianghua Feng $\mathbb{D}^{D}$, and Guangqiang Liu \\ School of Materials and Metallurgy, University of Science and Technology Liaoning, Anshan 114000, China \\ Correspondence should be addressed to Peng Han; hanpeng@ustl.edu.cn
}

Received 8 August 2019; Revised 15 October 2019; Accepted 21 October 2019; Published 16 November 2019

Academic Editor: Hao Zhang

Copyright (C) 2019 Liwen Zhou et al. This is an open access article distributed under the Creative Commons Attribution License, which permits unrestricted use, distribution, and reproduction in any medium, provided the original work is properly cited.

\begin{abstract}
Herein, two-dimensional (2D) single-action die compaction process of copper $(\mathrm{Cu})$ powder was simulated by the multiparticle finite element method (MPFEM) at particulate scale. The initial packing structure, generated by the discrete element method (DEM), was used as an input for the FEM model, where the mesh division of each particle was discretized. The evolution of macroand microscopic properties, such as relative density, stress distribution, particle deformation, void filling behavior, and force transmission, during compaction and pressure release processes have been systematically studied. The results revealed that the force is mainly concentrated on largely deformed regions of the particles during compaction and formed a contact force network, which hindered the densification process. In the compact, the shorter side of the large void edges rendered higher stress than the longer side. On the other hand, the stress distribution of small void edges remained uniform. After pressure release, large residual stress was observed at the contact area of the adjacent particles and the maximum stress was observed at the particles' edges. Moreover, the residual stress did not proceed to the interior of the particles. Meanwhile, the stress of large void edges has been completely released but exhibited a nonuniform distribution. The smaller fraction of void filling resulted in a larger reduction of the released stress after pressure removal. Also, the particles closer to the upper die exhibited higher average equivalent von Mises stress inside the particles during compaction and pressure release processes.
\end{abstract}

\section{Introduction}

Copper- $(\mathrm{Cu}-)$ based materials are widely employed in different industrial areas, such as metallurgy, mechanics, aeronautics, and aerospace. In particular, several $\mathrm{Cu}$-based smelting parts, including basic oxygen furnace steelmaking lance nozzle, are used in the metallurgical processes. With increasing demand of the smelting process, different types of oxygen lance nozzles, such as nozzle-twisted lance and variable angle and flow oxygen lance nozzle, have been successfully developed. Moreover, the nozzle-twisted lance cannot be fabricated by the conventional forging method due to its design complexity. In addition, the usual casting process results in shorter service life of nozzle-twisted lance. Recently, powder metallurgy (PM) technology has gained significant industrial focus for the fabrication of complex structural components. Herein, we aimed to utilize powder metallurgy technology to prepare nozzle-twisted lance with a complex structure. Powder forming process plays a critical role in the PM process. In the past decades, several experimental and theoretical studies have been carried out on the powder forming process. The experimental work is mainly focused on the forming theory and yield criteria. However, it's difficult to realize the characterization of the micromechanical properties of the forming process, therefore it is really hard to quantitatively characterize the local density and distribution, stress distribution, and particle flow behavior in the compact during and after compaction [1-7]. Moreover, as well known that in addition to the relative density, other properties such as local relative density and distribution and stress and distribution, as well as powder flow behavior, cannot be characterized in experiments. Moreover, the microscopic dynamic characteristics of particles cannot be studied during physical experiments, which hinder the detailed investigation of translation, rotation, interaction force, and deformation behavior of particles. Moreover, geometric nonlinearity, 
material nonlinearity, and contact nonlinearity of the forming process raise difficulties in the physical experiments [8-11]. Therefore, the macroscale continuous finite element method (FEM) is widely used to overcome these issues and analyze the local relative density and distribution and stress and distribution as well as powder flow, which has been used to numerically simulate single-action die forming process for pure metallic powders [12-16] and composite metallic powders [17-19]. However, the continuous mechanical method cannot describe the powder forming process due to the inherent properties of the particles. Hence, the discrete element method (DEM) is used to effectively simulate the compaction process [20-23] and flow [24-27] of different powder assemblies at a particulate scale. However, it has been reported that the effectiveness of DEM numerical simulations is largely dependent on small deformations or low relative densities [28].

In recent years, a multiparticle finite element method (MPFEM) is proposed to effectively overcome the deficiencies of DEM simulations. In the MPFEM, a single particle is considered as an individual entity and the mesh of each particle is discretized. Then, the densification of the compaction process is simulated by the FEM. In general, the MPFEM combines the characteristics of conventional FEM and DEM simulations and is capable of comprehensively simulating the compaction densification process of a powder, with large deformation at particulate scale, which cannot be achieved by FEM and DEM simulations. Hence, the MPFEM is widely used to investigate the influence of density distribution, particle size, and friction conditions on the forming process [29-37]. Furthermore, a series of studies has focused on the forming process of multicomponent particles and analyzed the influence of volume fraction of hard particles on the forming densification process [38-40]. In addition, the transition from one-dimensional spherical particles to two-dimensional spherical particles, mechanical behavior of contacting particles, and influence of small particles on the forming densification process have been studied in detail [41, 42]. However, to the best of our knowledge, the compaction of $\mathrm{Cu}$ powder from a particulate scale and corresponding microdynamics analysis, pressure unloading process, and densification mechanism have not been investigated in detail.

Herein, the single-action die compaction and pressure unloading of $\mathrm{Cu}$ powder are modeled by the two-dimensional (2D) MPFEM. Then, the initial packing structure, generated by using DEM simulations, was imported into the FEM model and the densification behavior of $\mathrm{Cu}$ particles is characterized. Meanwhile, the deformation behavior of the particles, void filling, and stress distribution are analyzed at a particulate scale. Finally, the influence of pressure unloading on stress evolution of the whole compact and particle is systematically studied.

\section{Simulation Model and Conditions}

2.1. Model Setup. The whole forming process of $\mathrm{Cu}$ powder, under single-action die compaction, was modeled by using commercial FEM software MSC. Marc. To realistically demonstrate the actual process, the random initial packing structures were generated by DEM dynamic modeling and, then, imported into the FEM model for compaction to realize the coupling, where each particle has been fully discretized into a finite element mesh. Previously, we have demonstrated the utilization of the DEM method to study the packing of various spherical and nonspherical particle packing systems [20-23]. To simplify the modeling process, Figure 1 presents the the DEM-generated initial packing structure before compaction and corresponding mesh division of an individual particle, where each particle contains 132 units and 169 nodes (Figure 1(b)). Herein, $\mathrm{Cu}$ particles are equal in size with a diameter of $1 \mathrm{~mm}$.

In the simulation, the constitutive equations of von Mises yield function and power-law relation were used to model the reference materials, as shown below:

$$
\sigma_{y}=C\left(\varepsilon_{0}+\bar{\varepsilon}\right)^{n}+D(\dot{\bar{\varepsilon}})^{k}
$$

where $\varepsilon_{0}$ refers to initial yield strain; $\bar{\varepsilon}$ corresponds to equivalent strain; $\dot{\bar{\varepsilon}}$ represents equivalent strain rate; and parameters $C, D, n$, and $k$ are material constants. Initially, the equivalent strain and equivalent strain rate were assumed to be zero to calculate Young's modulus $(Y)$ and initial yield strain by using $C$ and $n$ from the von Mises model. The von Mises stress can be given by

$$
\bar{\sigma}=\frac{\left[\left(\sigma_{1}-\sigma_{2}\right)^{2}+\left(\sigma_{2}-\sigma_{3}\right)^{2}\left(\sigma_{3}-\sigma_{1}\right)^{2}\right]^{1 / 2}}{\sqrt{2}},
$$

where $\sigma_{1}, \sigma_{2}$, and $\sigma_{3}$ represent the principal Cauchy stresses along the three main axes. The equivalent strain rate can be given as follows:

$$
\dot{\bar{\varepsilon}}=\left[\frac{2}{3\left(\varepsilon_{i j} \varepsilon_{i j}\right)}\right]^{1 / 2},
$$

where $\varepsilon_{i j}$ represents the strain tensor.

MSC. Marc used Cauchy stress (true stress) and logarithmic strain with updated Lagrange formulation. It is instructive to derive the stiffness matrices for the updated Lagrangian formulation, starting from the virtual work principle, by using the following equation:

$$
\int_{V_{0}} S_{i j} \delta E_{i j} \mathrm{~d} V=\int_{V_{0}} b_{i}^{0} \delta \eta_{i} \mathrm{~d} V+\int_{A_{0}} t_{i}^{0} \delta \eta_{i} \mathrm{~d} A,
$$

where $S_{i j}$ refers to the second Piola-Kirchhoff stress; $E_{i j}$ represents the Green-Lagrange strain; $b_{i}^{0}$ corresponds to the body force in the reference configuration; $t_{i}^{0}$ denotes the traction vector in the reference configuration; and $\eta_{i}$ refers to the virtual displacement.

2.2. Simulation Conditions. The boundary conditions in FEM simulations were as follows: displacement boundary condition was imposed via rigid upper punch; the position of the rigid die wall was fixed; and the change in density of the compact was determined by the change in displacement of the upper punch. The upper punch moved downwards at an assumed strain rate during compaction. One should note 


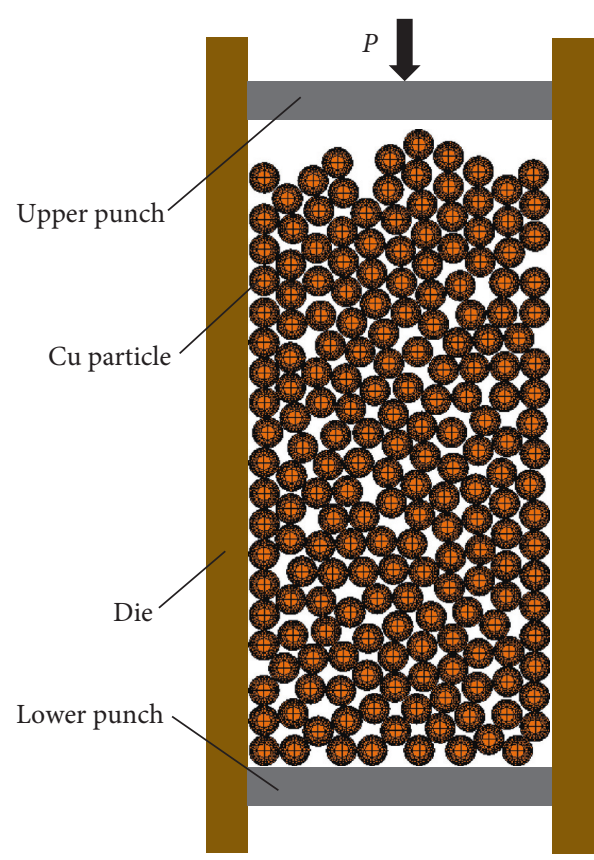

(a)

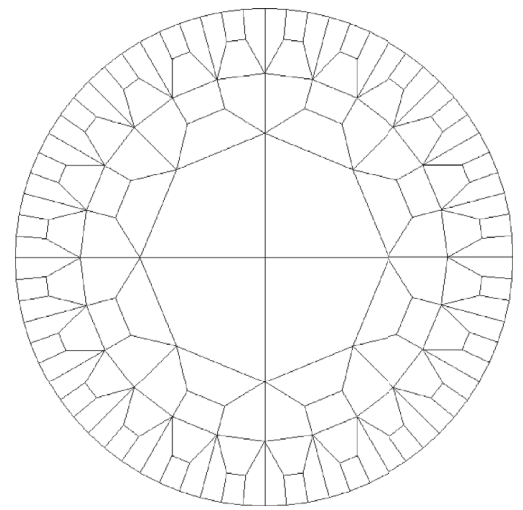

(b)

FIgURE 1: DEM generated (a) initial packing structure and (b) mesh division of an individual particle.

that the simulation results are not influenced by the strain rate due to the strain-rate insensitive nature of the material. Moreover, each particle is independent and deformable. Also, the relationship between the positions of particles can be determined by using a contact table to assess their contact state in the model setup. The contact between particles was controlled by "node to segment method" upon compaction, which is widely used in FEM simulations. The material was set to be elastoplastic, and the main parameters of the $\mathrm{Cu}$ powder are listed in Table 1. Based on the Coulomb friction model, the friction coefficient between the particles was set to be 0.2 . The punch and die were assumed to be rigid with smooth surfaces to reduce the friction between compaction equipment and $\mathrm{Cu}$ powder.

\section{Results and Discussion}

3.1. Pressure-Relative Density Relationship. It is worth mentioning that the compaction pressure $(P)$ plays a decisive role in the powder forming process. Figure 2 presents the relationship between the compaction pressure and relative density $(\rho)$ of the $\mathrm{Cu}$ powder during compaction, which indicates three distinct stages. First, in the initial stage, the particles slide to rearrange and fill the large pores in initial loose packing under a low compression pressure. Therefore, the relative density of the compact rapidly increased with a slight increase in pressure. Second, after a certain value, the relative density rapidly increased with a further increase in compaction pressure. Herein, the compression pressure exceeds the critical stress of the powder and the particles induce significant plastic deformation to fill the pores. Third, at a relative density of $\sim 0.95$, the change in relative density with respect to compaction pressure became insignificant, and the densification of the compact has transmitted from deformation of individual particles to bulk behavior. Hence, a small increase in relative density requires an extremely high compression pressure during this stage. In order to verify the accuracy and effectiveness of numerical simulations, we have also carried out single-action die compaction of $\mathrm{Cu}$ powder. Figure 2 shows the excellent consistency between experimental and computational results. Moreover, both curves tend to coincide with the increase of compression pressure. One should note that the present results are also consistent with the previously reported experimental and theoretical studies $[16,39]$.

In addition, the numerical simulation results were fitted by using a double logarithmic equation to demonstrate the validity and effectiveness of the applied numerical model as given below:

$$
m \log \ln \frac{\left(\rho_{m}-\rho_{0}\right) \rho}{\left(\rho_{m}-\rho\right) \rho_{0}}=\log P-\log M,
$$

where $\rho_{m}$ refers to the density of the fully dense metal, $\rho_{0}$ represents initial packing density of the compact, $\rho$ corresponds to the relative density of the compact, $P$ denotes compaction pressure, $M$ refers to compaction modulus, and $m$ denotes hardening index. Figure 3 presents the fitting of computational and experimental results, showing the high degree of linearity and confidence to the double-logarithm equation, which further confirms the robustness and effectiveness of the used model.

3.2. Macrostructural Characterization during and after Compaction. In addition to the relationship between relative density and compression pressure, the current study 
TABle 1: The material constants of $\mathrm{Cu}$ powder used in the current simulations.

\begin{tabular}{lcccc}
\hline Material & Young's modulus $E(\mathrm{GPa})$ & Poisson's ratio $v(-)$ & Hardening index $m(-)$ & Strength coefficient $A(\mathrm{MPa})$ \\
\hline $\mathrm{Cu}$ & 128 & 0.33 & 0.237 & 575.3 \\
\hline
\end{tabular}

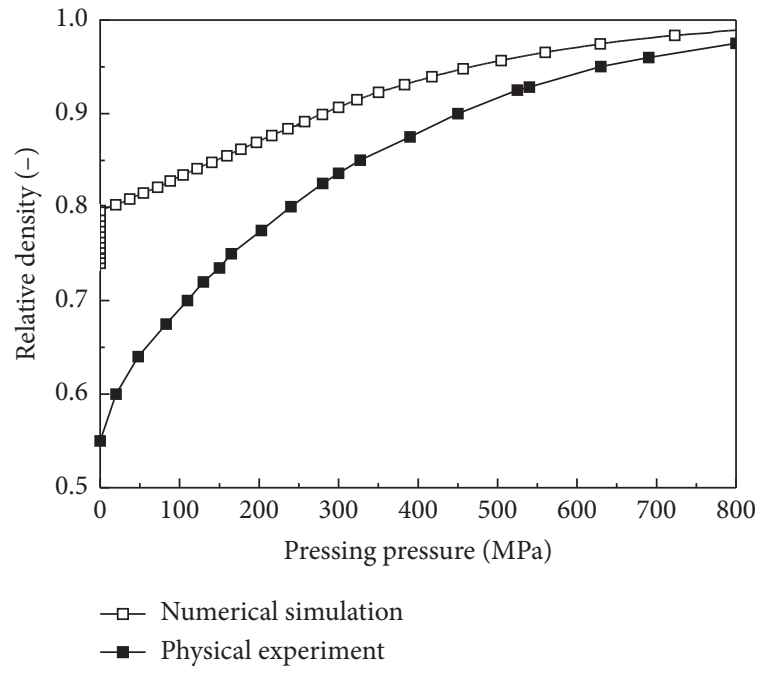

FIGURE 2: The relationship between compaction pressure and relative density.

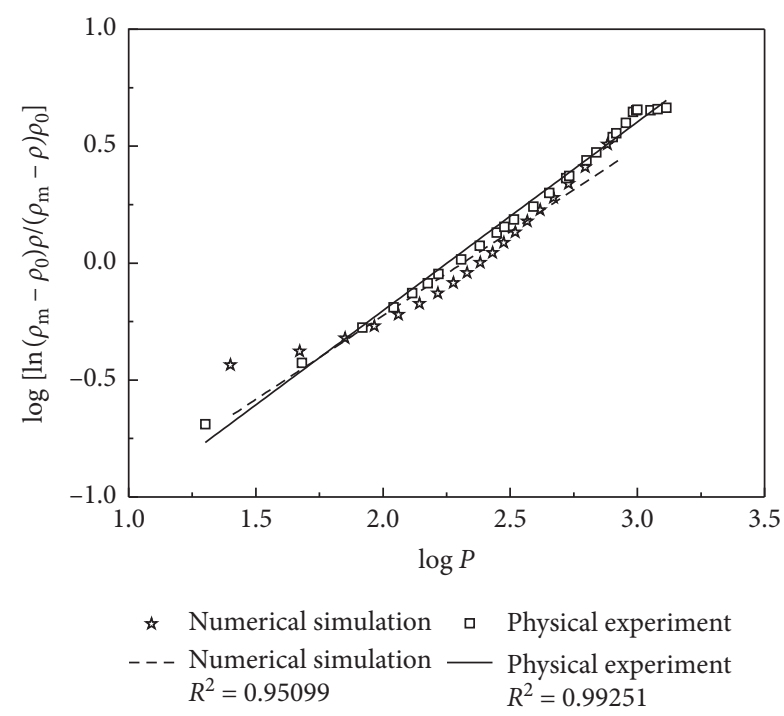

FIGURE 3: Fitting of the computational and experimental results with the double logarithmic equation.

unveils the macrocompaction mechanism of the powder compact. Figure 4 shows the equivalent von Mises stress distribution of the compact under different compression pressures. During the initial forming stage, the particles get into contact with each other and form a force network or force chain in the compact, which hinders the forming process. With the increase of compression pressure, the continuous network force chain gradually evolved into a surface, making the forming process more difficult. This also explains the transition of the $\rho$ - $P$ curve from Stage II to Stage III, as discussed earlier. Meanwhile, the contacting particles generated a large stress concentration, which is directly related to the deformation of the particles. If these parts are in contact with each other, a new force chain will be formed, which may hinder the densification process.

Moreover, the performance of the compact after unloading has been studied and results are presented in Figure 5, which shows the evolution of equivalent von Mises stress in the compact during unloading. It should be noted that the stress inside the compact gradually released with the decrease of pressure and the particles on the edge of the die wall easily formed an ordered structure. Despite the high stress, the residual stress distribution in these particles is relatively uniform. On the other hand, the stress of some particles in the center of the compact released in large quantity and resulted in small residual stress. Moreover, the residual stress at the void edge of incomplete filling is also low. The stress of the compact further released with the decrease of pressure. When the pressure is completely removed, the bottom of the compact cracked due to the absence of any binder. However, despite the complete separation of surrounding particles, the residual stress inside the particles did not change.

3.3. Microstructural Characterization during and after Compaction. Furthermore, the morphological evolution and stress distribution of two typical local structures, i.e., $A$ and $B$, as shown in Figure 4, were tracked during the forming process. Figure 6 shows the particle morphology of a local large void structure " $A$ " during the compaction and pressure release processes, the change of equivalent von Mises stress in the particle and void filling mechanism. When the two particles started to contact with each other, a large stress concentration initiated at the contact point. Then, the contact behavior of particles changed from point-contact to line-contact and the maximum stress area continuously increased at particles' edges. In addition, more particles participated in the void filling to fill the large voids, which have been formed under the "bridge" and "arching" structure. Hence, the deformation of particles gradually increased with the gradual shrinkage of voids, which led to a gradual increase in the contact surface between adjacent particles. Hence, a sharp increase in the stress concentration area has been observed at the edges. Meanwhile, a smaller part of the stress concentration appeared at the void edge. One should note that the stress concentration of the long side around the void remained low with the increase of pressure.

The morphology of the local microstructure and stress distribution inside the particles are studied after the pressure release. Figure 7 shows the evolution of particle morphology, void morphology, and equivalent von Mises stress during the pressure unloading of local structure " $A$." It can be readily observed that the particle and void morphology did 


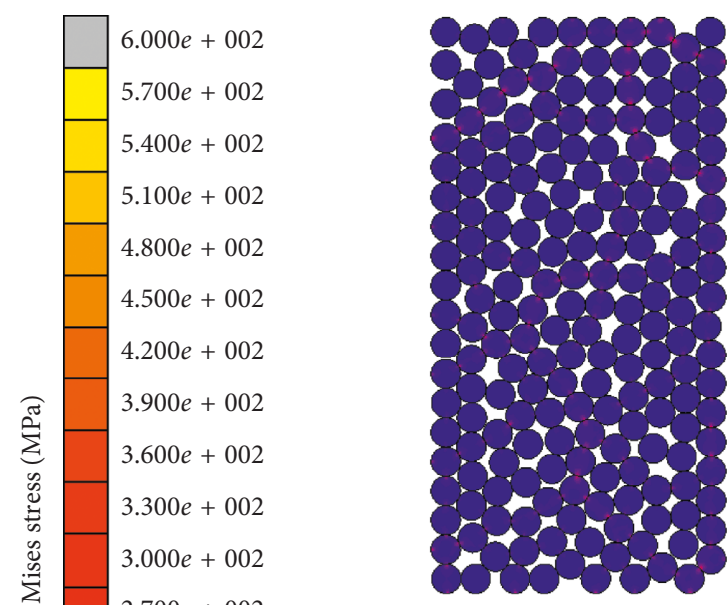

(a)

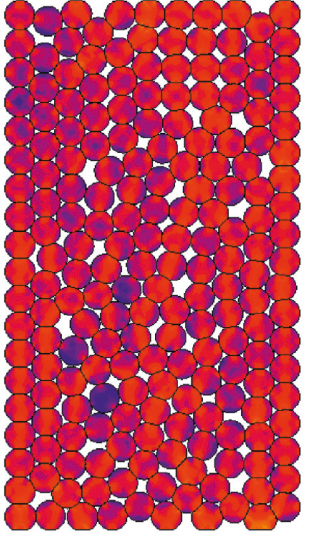

(b)

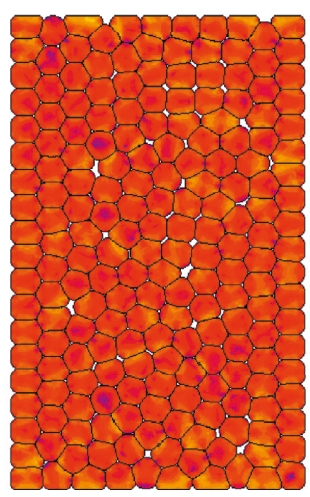

(d)

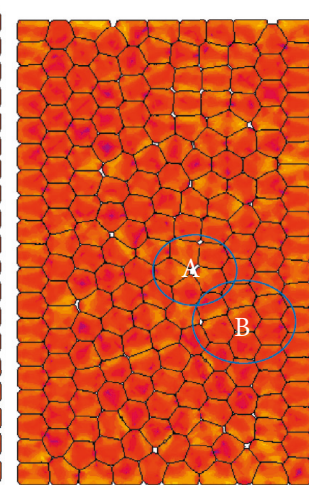

(e)

FIGURE 4: Distribution of equivalent von Mises stress for compacts with various pressures: (a) $10 \mathrm{MPa}$, (b) $200 \mathrm{MPa}$, (c) $400 \mathrm{MPa}$, (d) $600 \mathrm{MPa}$, and (e) $800 \mathrm{MPa}$.

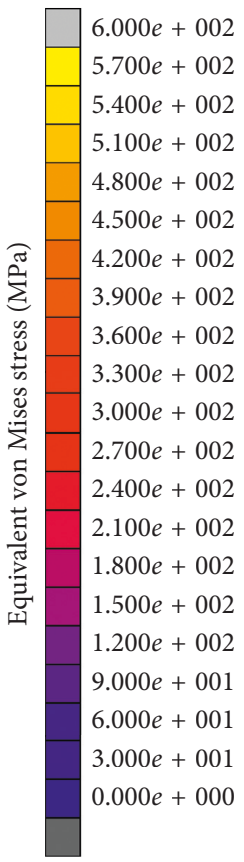

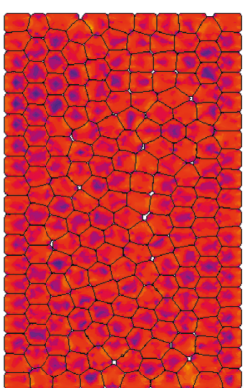

(a)

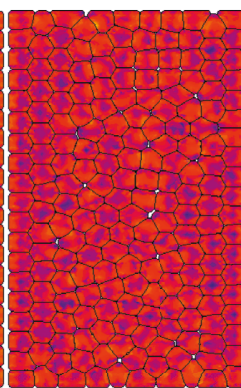

(b)

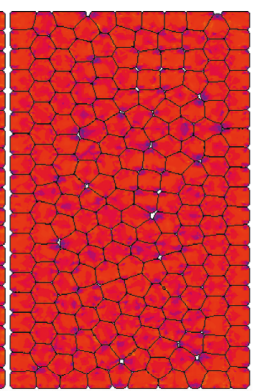

(c)

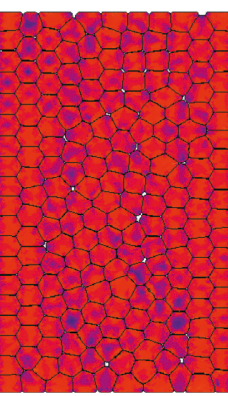

(d)

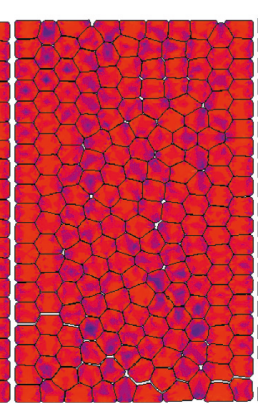

(e)

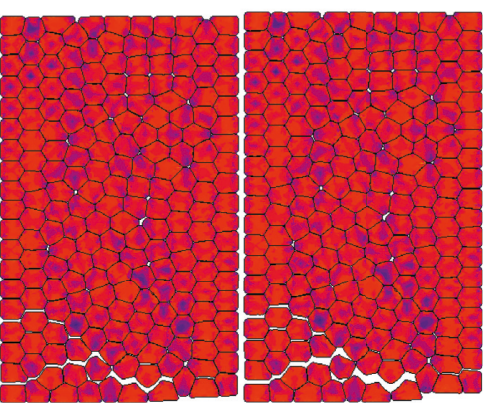

(f)

(g)

Figure 5: Distribution of equivalent von Mises stress after pressure unloading: (a) $800 \mathrm{MPa}$, (b) $500 \mathrm{MPa}$, (c) $300 \mathrm{MPa}$, (d) $100 \mathrm{MPa}$, and (e)-(g) $0 \mathrm{MPa}$. 


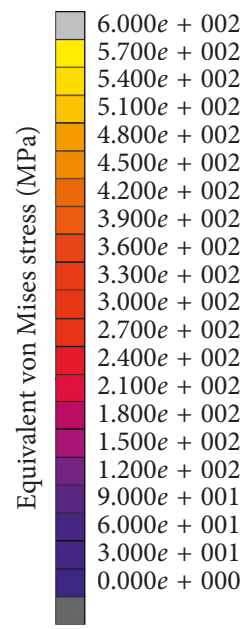

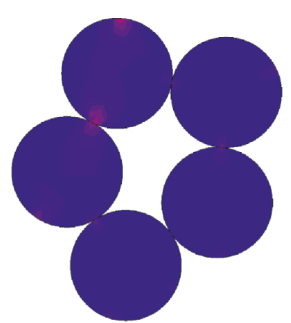

(a)

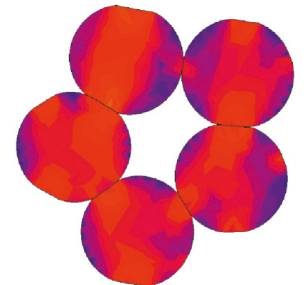

(b)

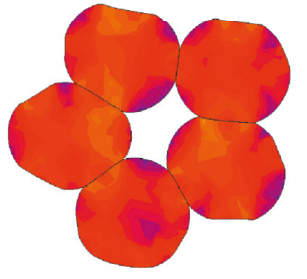

(c)

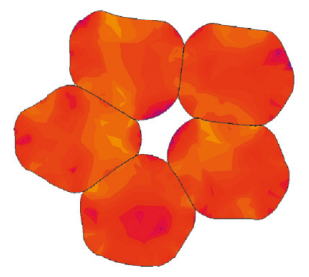

(d)

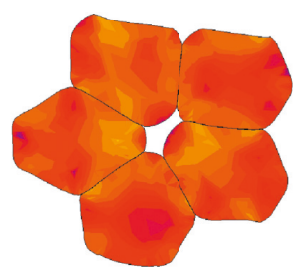

(e)

FIGURE 6: Equivalent von Mises stress distribution of local structure " $A$," as shown in Figure 4: (a) $10 \mathrm{MPa}$, (b) $200 \mathrm{MPa}$, (c) $400 \mathrm{MPa}$, (d) $600 \mathrm{MPa}$, and (e) $800 \mathrm{MPa}$.

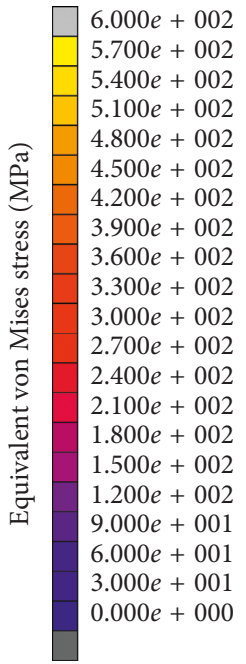

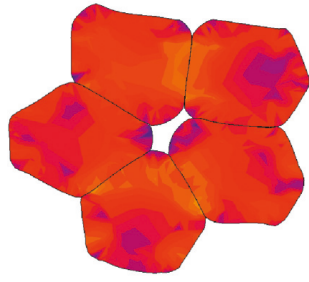

(a)

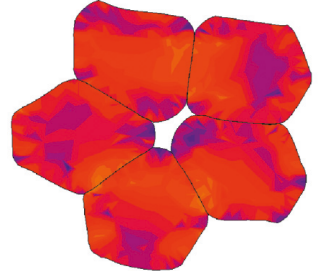

(b)

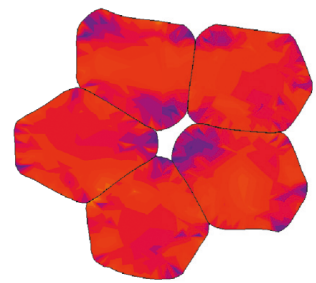

(c)

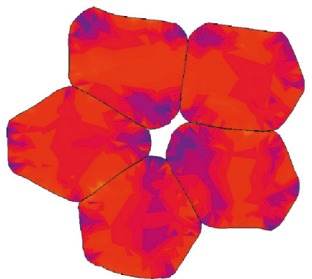

(d)

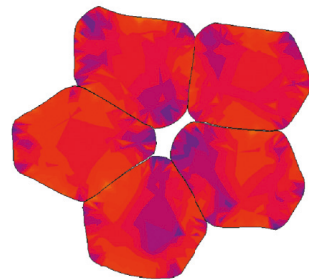

(e)

Figure 7: Equivalent von Mises stress distribution of local structure “ $A$ ” after pressure release: (a) $800 \mathrm{MPa}$, (b) $500 \mathrm{MPa}$, (c) $300 \mathrm{MPa}$, (d) $100 \mathrm{MPa}$, and (e) $0 \mathrm{MPa}$.

not change with the gradual removal of applied pressure. However, the stress inside the particles gradually decreased with the pressure release, but a large amount of residual stress has been observed at the contact surface of adjacent particles. In addition, instead of the interior surface, the maximum stress appeared at the particles' edges. Hence, the stress inside the particle and the void edge has been completely released.

Furthermore, we have investigated the stress evolution behavior at the void edge during compaction and pressure release, as shown in Figure 8. Figure 8(a) shows the void morphology and residual stress distribution after pressure unloading. It can be clearly seen that the residual stress at the void edge is low and not evenly distributed. To establish the stress evolution behavior, we have quantitatively analyzed the stress distribution of the void edge during compaction and after unloading. As shown in Figure 8(b), when the less volume of particles is filled into the void, the higher stress reduction has been observed after unloading. For instance, at node 20290, the stress value under compaction $(P=800 \mathrm{MPa})$ was found to be $\sim 360 \mathrm{MPa}$, which has been reduced to $\sim 80 \mathrm{MPa}$ after unloading. On the other hand, the higher volume of particles results in a smaller stress reduction after unloading. At node 21547 , the stress value under compaction $(P=800 \mathrm{MPa})$ was found to be $\sim 245 \mathrm{MPa}$, which was reduced to only $\sim 240 \mathrm{MPa}$ after unloading. Therefore, local "bridging" and "arching" structures, formed by particles, should be avoided to obtain the compact uniform distribution of a void structure. In addition, the large stress concentration and uneven void distribution also exist in the final compact, leading to an uneven deformation of surrounding particles. Therefore, the uniform void filling is of 

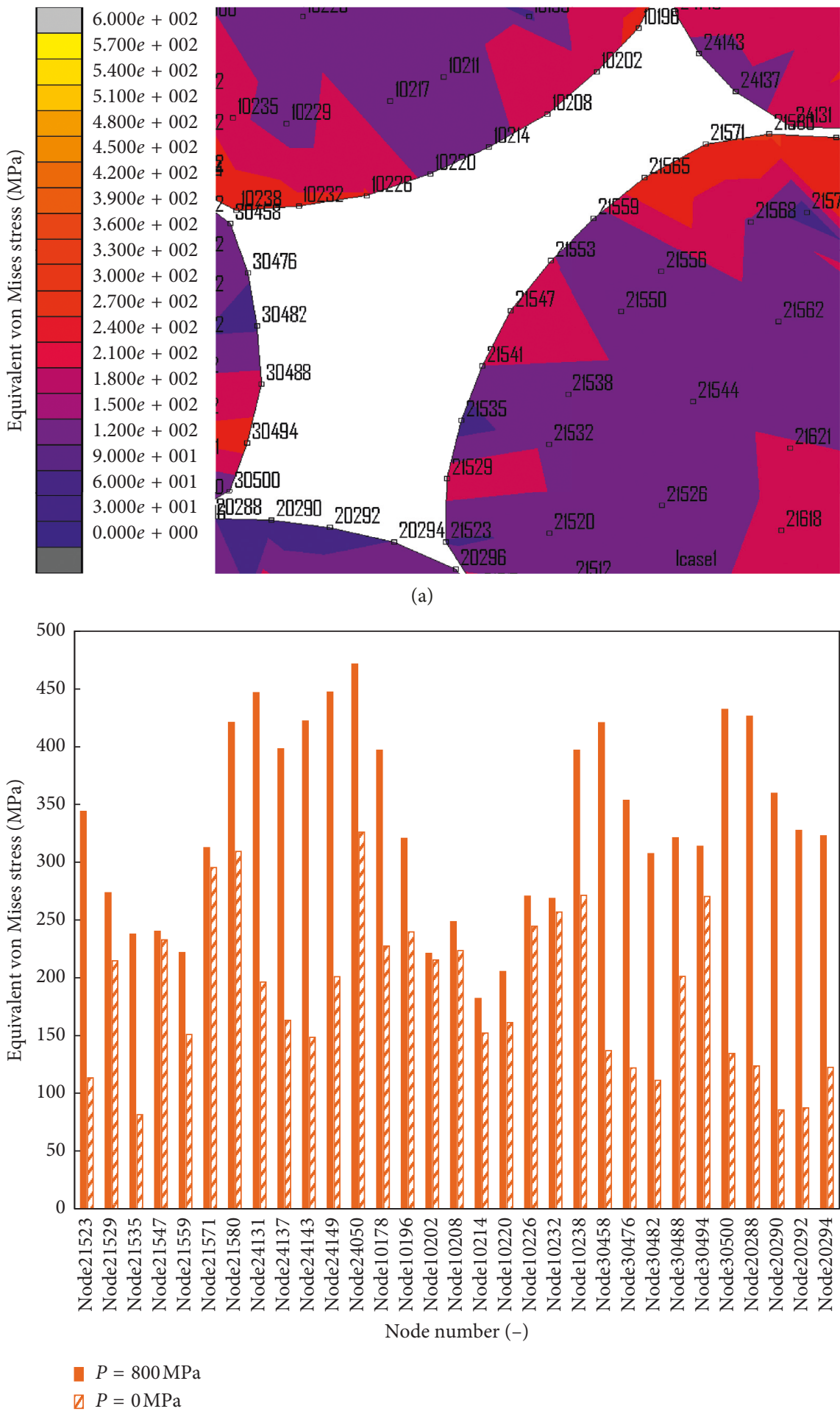

(b)

Figure 8: Equivalent von Mises stress distribution in the pore perimeter, shown in Figure 7, after pressure release.

utmost significance to avoid excessive residual stress gradient in the particles after unloading.

Figure 9 shows the particle morphology, void morphology, and evolution of equivalent von Mises stress inside the particle of a local structure " $B$," shown in Figure 4, during compaction. It can be readily observed that the particle deformation of local structure " $B$ " is relatively uniform during compaction and void filling is completed by three particles. Similar to other structures, the stress at the center of a particle is much smaller than the stress at the edge of a particle. Moreover, the morphology and residual stress of the local structure " $B$ " have been analyzed after pressure 


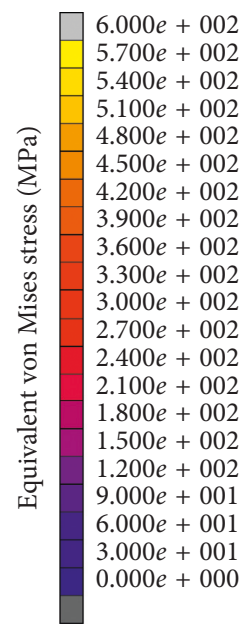

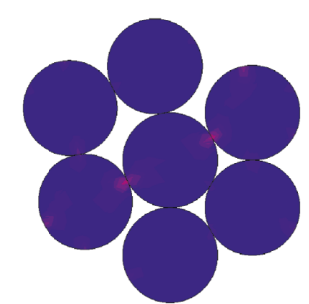

(a)

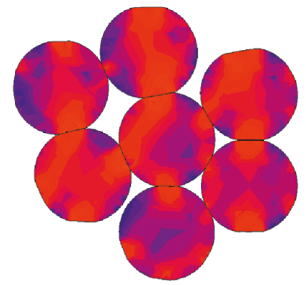

(b)

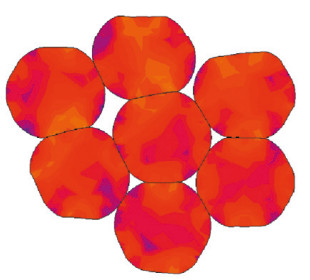

(c)

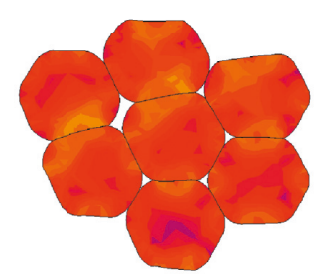

(d)

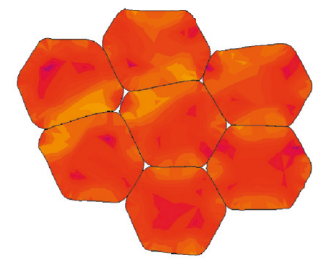

(e)

Figure 9: Equivalent von Mises stress distribution of local structure “ $B$ ”: (a) $10 \mathrm{MPa}$, (b) $200 \mathrm{MPa}$, (c) $400 \mathrm{MPa}$, (d) $600 \mathrm{MPa}$, and (e) $800 \mathrm{MPa}$.

unloading to explore the evolution of equivalent von Mises stress inside the particles.

Figure 10 shows the particle morphology, void morphology, and evolution of equivalent von Mises stress inside the particles of local structure " $B$ " during pressure unloading. One should note that the particle morphology and void morphology exhibited a negligible change after pressure unloading, but the stress inside the particle has been significantly changed. During pressure release, the stress at the center of particles initially decreased to a minimum value with pressure release, followed by a gradual redistribution in the particles. At $P=0 \mathrm{MPa}$, the residual stress in the particle and void edge attained a minimum value. Similar to the results in Figure 7, large residual stress has been observed at the contact point of adjacent particles and the spring back led to crack initiation and propagation in the compact [43].

Furthermore, the stress evolution has been analyzed by studying the variation of average equivalent von Mises stress during the forming process of the particles " $A$," " $B$," and " $C$," shown in Figure 10, during compaction and pressure release (Figure 11). Clearly, the variation of average equivalent von Mises stress can be divided into three distinct stages. Initially, we have not observed any stress inside the particles during the rearrangement stage, which can be ascribed to the absence of any locking mechanism between particles. In the $2^{\text {nd }}$ stage, the particles begin to produce large plastic deformation and the average equivalent von Mises stress rapidly increases to a maximum value. In the $3^{\text {rd }}$ stage, once the pressure is removed, the average equivalent von Mises stress inside the particles slightly decreases to a value of $\sim 260 \mathrm{MPa}$. Moreover, the particles closer to the upper die exhibited higher average equivalent von Mises stress inside the particles during compaction and pressure release processes.

\section{Conclusions}

The dynamic process of $\mathrm{Cu}$ powder die compaction has been modeled by the multiple-particle finite element method (MPFEM) coupled with the discrete element method (DEM).
The influence of compaction and pressure release processes on macro- and microscopic properties of the compact has been systematically studied. Moreover, the powder forming behavior and mechanism have been studied, and the stress distribution, stress transmission, void filling, and particle morphology evolution are analyzed from particulate scale. The following conclusions can be drawn from the current study:

(1) During the forming process, the contacting particles resulted in a large deformation, which is directly related to the stress concentration. Moreover, these particles formed a chain of forces, which hindered the densification process. After pressure removal, the internal stress of the compact and some particles, located in the center of the compact, is completely released. However, the residual stress inside the particles, located at the edge of the die wall, exhibited a large value with uniform stress distribution.

(2) The filling of large voids requires large deformation of multiple particles in the compact. Moreover, the stress concentration area at the particles' edge continuously increased with the shrinkage of void size. Meanwhile, a small portion of the stress concentration appeared on the longer side of the void edge. After pressure release, large residual stress has been observed in the contact area of adjacent particles and, instead of the interior region, the maximum stress only appeared at particles' edges.

(3) After pressure release, the stress inside the particles and at the void edges has been completely released. However, this stress also exhibited a nonuniform distribution. In addition, different positions of the void edge exhibited different levels of stress release. The smaller fraction of the pore filling resulted in a larger reduction of the stress after pressure release and vice versa.

(4) Compared with the larger voids, which are formed by the "bridge" and "arch" structures, the void size in the local dense random packing structure is smaller and these voids do not require a large number of particles 


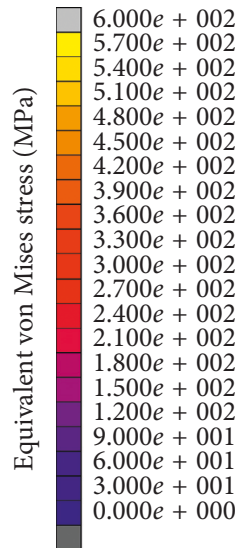

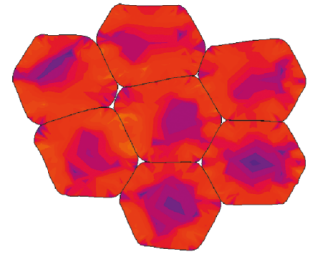

(a)

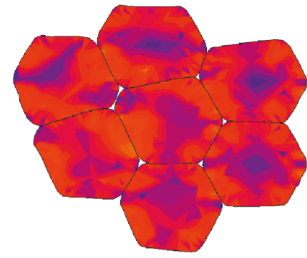

(b)

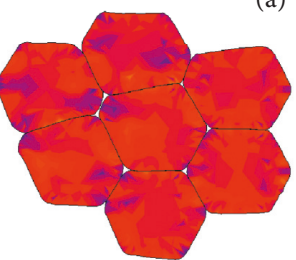

(c)

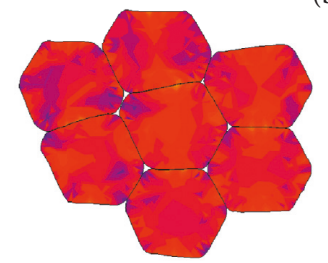

(d)

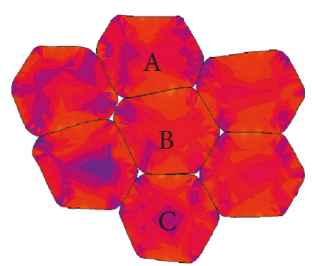

(e)

Figure 10: Equivalent von Mises stress distribution in local structure " $B$ " during pressure release: (a) $800 \mathrm{MPa}$, (b) $500 \mathrm{MPa}$, (c) $300 \mathrm{MPa}$, (d) $100 \mathrm{MPa}$, and (e) $0 \mathrm{MPa}$.

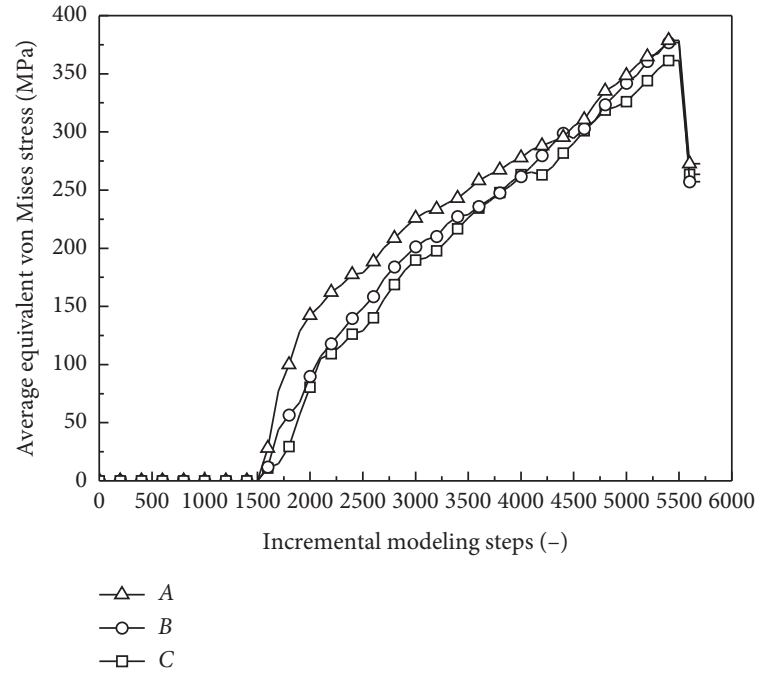

FIgURE 11: Average equivalent von Mises stress distribution of particles " $A$," " $B$ " and " $C$," shown in Figure 10, during compaction and pressure release processes.

to fill. Therefore, the contact area of adjacent particles and the stress concentration area are smaller than those which are formed by the "bridge" and "arch"structures. After pressure release, the interior stress has been completely released, but a small amount of residual stress remained at the contact point of adjacent particles. Moreover, the interior of particles, which are closer to the upper die, exhibited a higher average equivalent von Mises stress.

\section{Data Availability}

The data used to support the findings of this study are included within the article.

\section{Conflicts of Interest}

The authors declare that there are no conflicts of interest regarding the publication of this paper.

\section{Acknowledgments}

The authors are grateful to the National key R\&D Project of China (2017YFC0805100) and Fundamental Research Funds for University of Science and Technology Liaoning (2018QN13) for the financial support of the current work.

\section{References}

[1] S. Shima and M. Oyane, "Plasticity theory for porous metallurgy," International Journal of Mechanical Science, vol. 18, no. 6, pp. 285-291, 1971.

[2] H. A. Kuhn and C. L. Downey, "Deformation characteristics and plasticity theory of sintered powder materials," International Journal of Powder Metallurgy, vol. 7, no. 1, pp. 15-25, 1971.

[3] R. J. Green, "A plasticity theory for porous solids," International Journal of Mechanical Sciences, vol. 14, no. 3, pp. 215-224, 1972.

[4] A. L. Gurson, "Continuum theory of ductile rupture by void nucleation and growth: part I-yield criteria and flow rules for porous ductile media," Journal of Engineering Materials and Technology, vol. 99, no. 1, pp. 2-15, 1977.

[5] S. M. Doraivelu, H. L. Gegel, J. S. Gunasekera, J. C. Malas, J. T. Morgan, and J. F. Thomas, "A new yield function for compressible materials," International Journal of Mechanical Sciences, vol. 26, no. 9-10, pp. 527-535, 1984.

[6] A. K. Eksi and A. H. Yuzbasioglu, "Effect of sintering and pressing parameters on the densification of cold isostatically pressed Al and Fe powders," Materials \& Design, vol. 28, no. 4, pp. 1364-1368, 2007.

[7] A. R. Khoei, A. R. Azami, and S. Azizi, "Computational modeling of 3D powder compaction processes," Journal of Materials Processing Technology, vol. 185, no. 3, pp. 166-172, 2007.

[8] K. Biswas, "Comparison of various plasticity models for metal powder compaction processes," Journal of Materials Processing Technology, vol. 166, no. 1, pp. 107-115, 2005.

[9] S. M. Tahir, A. K. Ariffin, and M. S. Anuar, "Finite element modelling of crack propagation in metal powder compaction using Mohr-Coulomb and elliptical cap yield criteria," Powder Technology, vol. 202, no. 1-3, pp. 162-170, 2010. 
[10] H. Diarra, V. Mazel, V. Busignies, and P. Tchoreloff, "FEM simulation of the die compaction of pharmaceutical products: influence of visco-elastic phenomena and comparison with experiments," International Journal of Pharmaceutics, vol. 453, no. 2, pp. 389-394, 2013.

[11] M. Oyane, S. Shima, and Y. Kono, "Thoery of plasticity for porous metals," Bulletin of JSME, vol. 16, no. 99, pp. 1254$1262,1973$.

[12] N. A. Fleck, L. T. Kuhn, and R. M. McMeeking, "Yielding of metal powder bonded by isolated contacts," Journal of the Mechanics and Physics of Solids, vol. 40, no. 5, pp. 1139-1162, 1992.

[13] X. An, Z. Xing, and C. Jia, "Cold compaction of copper powders under mechanical vibration and uniaxial compression," Metallurgical and Materials Transactions A, vol. 45, no. 4, pp. 2171-2179, 2014.

[14] X. An, Y. Zhang, Y. Zhang, and S. Yang, "Finite element modeling on the compaction of copper powder under different conditions," Metallurgical and Materials Transactions A, vol. 46, no. 8, pp. 3744-3752, 2015.

[15] Y. X. Zhang, X. Z. An, and Y. L. Zhang, "Multi-particle FEM modeling on microscopic behavior of 2D particle compaction," Applied Physics A, vol. 118, no. 3, pp. 1015-1021, 2015.

[16] P. Han, X. Z. An, Y. X. Zhang, and Z. S. Zou, "FEM modeling on the compaction of Fe and $\mathrm{Al}$ composite powders," Journal of Mining and Metallurgy, Section B: Metallurgy, vol. 51, no. 2, pp. 163-171, 2015.

[17] F. Huang, X. An, Y. Zhang, and A. B. Yu, "Multi-particle FEM simulation of $2 \mathrm{D}$ compaction on binary $\mathrm{Al} / \mathrm{SiC}$ composite powders," Powder Technology, vol. 314, pp. 39-48, 2017.

[18] K. T. Kim and J. H. Cho, "A densification model for mixed metal powder under cold compaction," International Journal of Mechanical Sciences, vol. 43, no. 12, pp. 2929-2946, 2001.

[19] P. Han, X. An, Y. Zhang et al., "Particulate scale MPFEM modeling on compaction of $\mathrm{Fe}$ and $\mathrm{Al}$ composite powders," Powder Technology, vol. 314, pp. 69-77, 2017.

[20] X. Z. An, R. Y. Yang, K. J. Dong, R. P. Zou, and A. B. Yu, "Micromechanical simulation and analysis of one-dimensional vibratory sphere packing," Physical Review Letters, vol. 95, Article ID 205502, 2005.

[21] A. B. Yu, X. Z. An, R. P. Zou, R. Y. Yang, and K. Kendall, "Selfassembly of particles for densest packing by mechanical vibration," Physical Review Letters, vol. 97, Article ID 265501, 2006.

[22] B. Zhao, X. An, Y. Wang, Q. Qian, X. Yang, and X. Sun, "DEM dynamic simulation of tetrahedral particle packing under 3D mechanical vibration," Powder Technology, vol. 317, pp. 171180, 2017.

[23] C. L. Martin and D. Bouvard, "Isostatic compaction of bimodal powder mixtures and composites," International Journal of Mechanical Sciences, vol. 46, no. 6, pp. 907-927, 2004.

[24] H. Zhang, B. Xiong, X. An, C. Ke, and J. Chen, "Numerical prediction on the drag force and heat transfer of non-spherical particles in supercritical water," Powder Technology, 2019.

[25] H. Zhang, B. Xiong, X. An, C. Ke, and G. Wei, "Numerical investigation on the effect of the incident angle on momentum and heat transfer of spheroids in supercritical water," Computers \& Fluids, vol. 179, no. 30, pp. 533-542, 2019.

[26] G. C. Wei, H. Zhang, X. Z. An, and S. Q. Jiang, "Influence of particle shape on microstructure and heat transfer characteristics in blast furnace raceway with CFD-DEM approach," Powder Technology, 2019.

[27] G. Wei, H. Zhang, X. An, B. Xiong, and S. Jiang, "CFD-DEM study on heat transfer characteristics and microstructure of the blast furnace raceway with ellipsoidal particles," Powder Technology, vol. 346, pp. 350-362, 2019.

[28] I. Sridhar, N. A. Fleck, and A. R. Akisanya, "Cold compaction of an array of cylindrical fibres," International Journal of Mechanical Sciences, vol. 43, no. 3, pp. 715-742, 2001.

[29] I. M. Cameron and D. T. Gethin, "Exploration of die wall friction for powder compaction using a discrete finite element modelling technique," Modelling and Simulation in Materials Science and Engineering, vol. 9, no. 4, pp. 289-307, 2001.

[30] X. J. Xin, P. Jayaraman, G. Jiang, R. H. Wagoner, and G. S. Daehn, "Explicit finite element method simulation of consolidation of monolithic and composite powders," Metallurgical and Materials Transactions A, vol. 33, no. 8, pp. 2649-2658, 2002.

[31] K. Mori and R. Kuzime, "Microscopic approach of powder compaction using finite element method," International Journal of Mechanical Sciences, vol. 44, no. 4, pp. 793-807, 2002.

[32] A. Zavaliangos, "A multiparticle simulation of powder compaction using finite element discretization of individual particles,” MRS Proceedings, vol. 731, pp. 733-717, 2002.

[33] A. T. Procopio and A. Zavaliangos, "Simulation of multi-axial compaction of granular media from loose to high relative densities," Journal of the Mechanics and Physics of Solids, vol. 53, no. 7, pp. 1523-1551, 2005.

[34] K. H. Lee, J. M. Lee, and B. M. Kim, "Densification simulation of compacted $\mathrm{Al}$ powders using multi-particle finite element method," Transactions of Nonferrous Metals Society of China, vol. 19, no. 1, pp. 68-75, 2009.

[35] J.-F. Jerier, B. Hathong, V. Richefeu et al., "Study of cold powder compaction by using the discrete element method," Powder Technology, vol. 208, no. 2, pp. 537-541, 2011.

[36] B. Harthong, J.-F. Jérier, V. Richefeu et al., "Contact impingement in packings of elastic-plastic spheres, application to powder compaction," International Journal of Mechanical Sciences, vol. 61, no. 1, pp. 32-43, 2012.

[37] F. Güner, Ö. N. Cora, and H. Sofuoğlu, "Numerical modeling of cold powder compaction using multi particle and continuum media approaches," Powder Technology, vol. 271, pp. 238-247, 2015.

[38] W. Wu, G. Jiang, R. H. Wagoner, and G. S. Daehn, "Experimental and numerical investigation of idealized consolidation," Acta Materialia, vol. 48, no. 17, pp. 4323-4330, 2000.

[39] J. Zhang, "A study of compaction of composite particles by multi-particle finite element method," Composites Science and Technology, vol. 69, no. 13, pp. 2048-2053, 2009.

[40] B. Harthong, J.-F. Jérier, P. Dorémus, D. Imbault, and F.-V. Donzé, "Modeling of high-density compaction of granular materials by the discrete element method," International Journal of Solids and Structures, vol. 46, no. 18-19, pp. 3357-3364, 2009.

[41] B. Harthong, D. Imbault, and P. Dorémus, "The study of relations between loading history and yield surfaces in powder materials using discrete finite element simulations," Journal of The Mechanics and Physics of Solids, vol. 60, no. 4, pp. 784-801, 2012.

[42] Y. Y. Foo, Y. Sheng, and B. J. Briscoe, "An experimental and numerical study of the compaction of alumina agglomerates," International Journal of Solids and Structures, vol. 41, no. 21, pp. 5929-5943, 2004.

[43] R. Zhou, L.-h. Zhang, B.-y. He, and Y.-h. Liu, "Numerical simulation of residual stress field in green power metallurgy compacts by modified Drucker-Prager Cap model," Transactions of Nonferrous Metals Society of China, vol. 23, no. 8, pp. 2374-2382, 2013. 


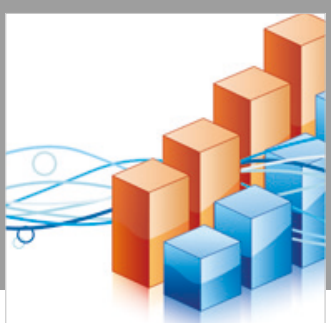

Advances in

Operations Research

\section{-n-m}
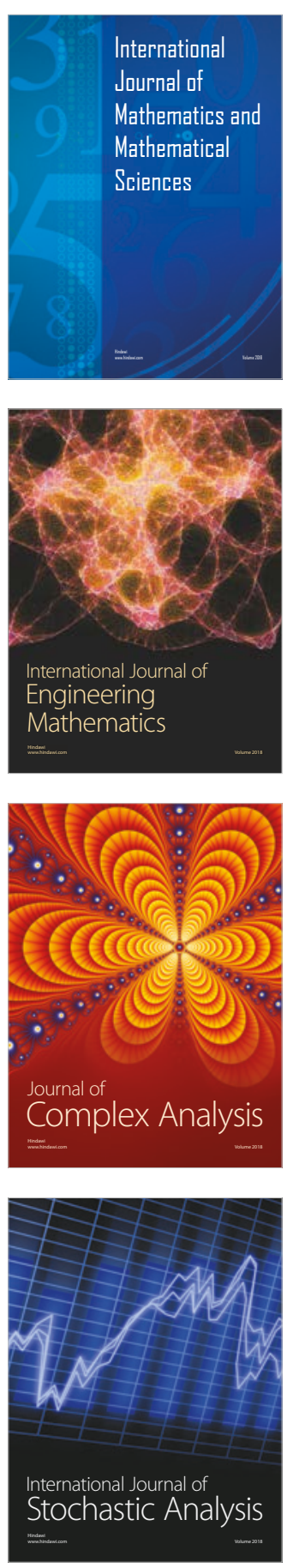
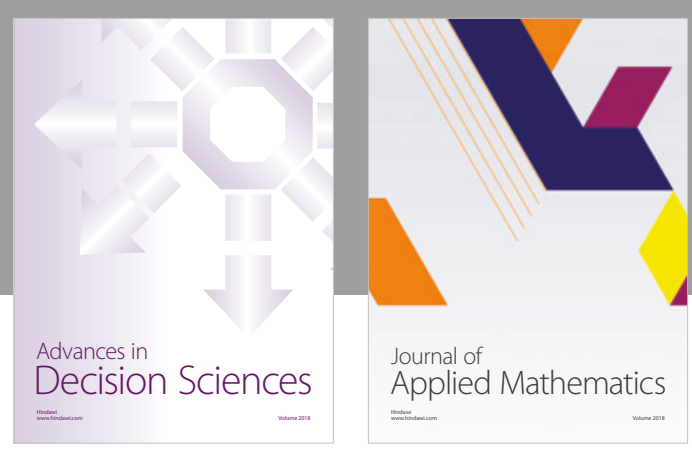

Journal of

Applied Mathematics
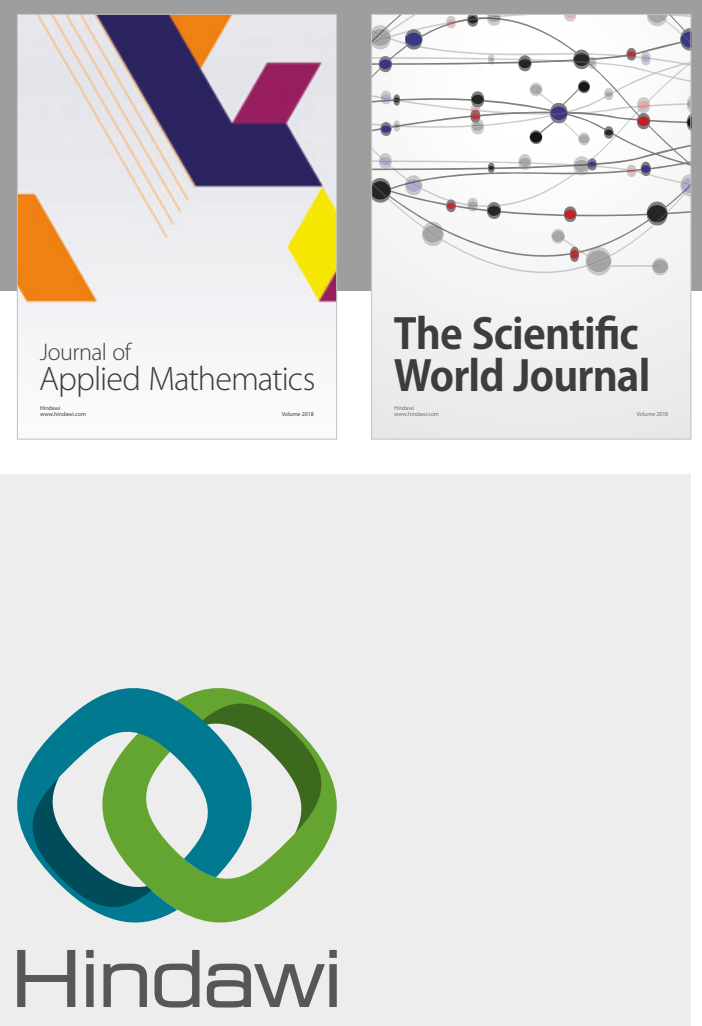

Submit your manuscripts at

www.hindawi.com

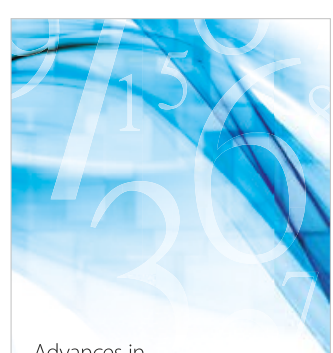

Advances in
Numerical Analysis
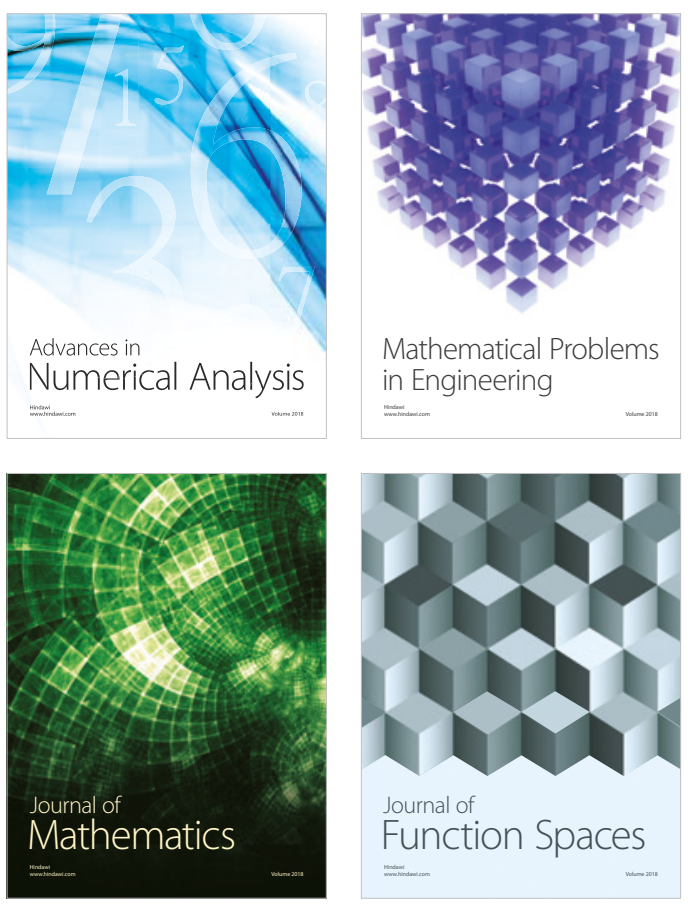

Mathematical Problems in Engineering

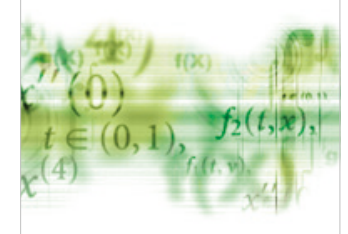

International Journal of

Differential Equations

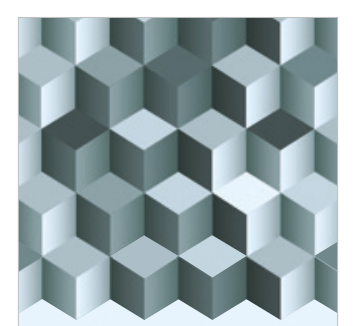

Journal of

Function Spaces

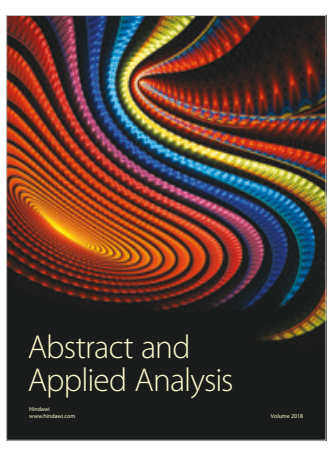

The Scientific

World Journal

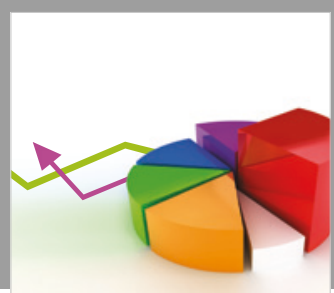

Journal of

Probability and Statistics
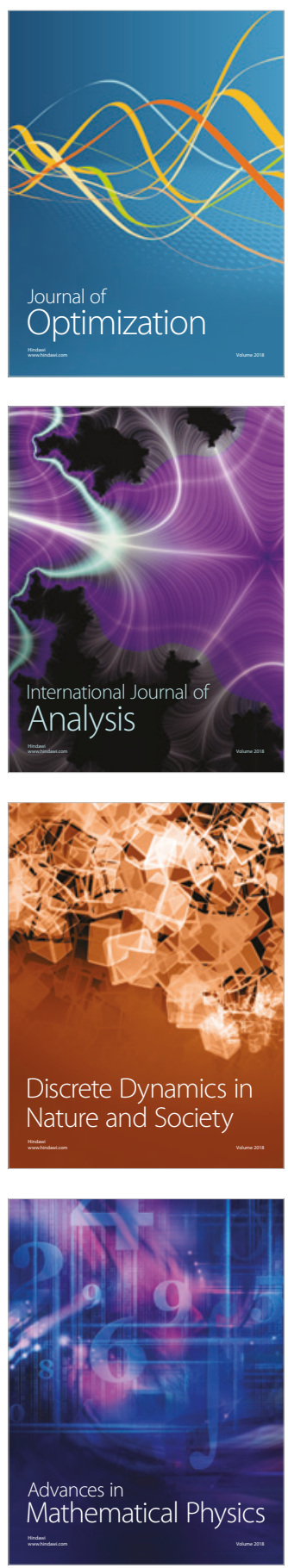